www.jmscr.igmpublication.org

Impact Factor 5.244

Index Copernicus Value: 83.27

ISSN (e)-2347-176x ISSN (p) 2455-0450

crossref DOI: _https://dx.doi.org/10.18535/jmscr/v4i12.106

\title{
A Study of HIV in Elderly Patients with Special Reference to Socio- Demographic Profile and Response to Anti Retroviral therapy
}

\author{
Authors \\ Miranda Pegu', Sujata Hazarika ${ }^{2}$, Neelakshi Mahanta ${ }^{3}$, Swaroop Kumar Baruah ${ }^{4}$ \\ ${ }^{1}$ Registrar Department of PM\&R, ${ }^{2}$ Assisstant Professor, Department of PM\&R \\ ${ }^{3}$ Associate Professor, Department of Medicine, ${ }^{4}$ Professor, Department of Medicine \\ Gauhati Medical college and hospital, Guwahati, Assam, India.
}

Corresponding Author

Miranda Pegu

Email:drmirandapegu@gmail.com

\begin{abstract}
Background: While HIV infection is commonly thought to affect younger adults, there are an increasing number of patients over 50 years of age living with the condition. With the introduction of highly active antiretroviral therapy, survival following HIV diagnosis has risen dramatically and HIV infection has evolved from an acute disease process to a chronic medical condition.

Aims and Objective: To determine the prevalence of HIV in elderly, socio-demographic profile and response to ART.

Materials and Method: This retrospective observational study was conducted in a tertiary care hospital in north eastern part of India. Out of 4085 registered cases between may 2005 to December 2013, a total of 50 patients who are aged over 60 years were included in the study.

Results: Prevalence of elderly was $1.22 \%$. Mean age at presentation was 63.44 yrs. 42(84\%) were males and $8(16 \%)$ were females. Patients from rural (54\%) background was slightly higher as compared to urban (46\%) background. Heterosexual was the most common mode of transmission 34/50 (68\%).Most of the cases were employed and literate. Sero-conversion was observed in 18 cases out of 49 married patient. Extra-pulmonary TB was the commonest Opportunistic infection. CD4 cell count increases significantly with ART. Mortality was associated with lower CD4 count at presentation.

Conclusion: Incidence of HIV in elderly is on the rising trend due to more case detection and effective treatment. Special attention should be paid to older women as under reporting is very common due to gender bias, social stigma and neglect. ART is very effective even in elderly hence no stone should be left unturned to detect HIV infection in older adults.

KEYWORDS: ART (Antiretroviral therapy), CD4 cell count, Elderly, HIV, Socio-demographic profile.
\end{abstract}

\section{INTRODUCTION}

While HIV infection is commonly thought to affect younger adults, there are an increasing number of patients over 50 years of age living with the condition. UNAIDS (United Nations Programme on HIV and AIDS) and WHO estimate that of the 40 million people living with HIV/AIDS in the world, approximately 2.8 million are 50 years and older. Between 11 and $15 \%$ of US AIDS cases occur in people over age $50^{(1)}$. HIV positive young adults transition into older adulthood and also acquire other age related 
co-morbidities. With the introduction of ART, HIV-infected patients live longer and the number of new HIV diagnoses in older patients rise, clinicians need to be aware of these trends and become familiar with the management of HIV infection in the older patient. The rise in overall number of elderly persons with HIV may be a result of late diagnosis or due to the effectiveness of potent therapy currently available to treat HIV infection. The number of older adults vulnerable to HIV/AIDS infection suggest that older adults may not be aware of or protecting themselves from the risk factors associated with HIV/AID. Often, older adults are not provided the information necessary to help protect themselves against infection. This is due in part to the general perception that the older adult population is not at risk for HIV, and society's reluctance to discuss behaviours that increase risk for transmission of $\mathrm{HIV}^{(2)}$. Though many literatures are available worldwide on HIV in elderly, there is dearth of such type of studies in India. Therefore this study is taken up with the following objectives

\section{AIMS AND OBJECTIVES}

1) To determine the prevalence of HIV in elderly.

2) To determine the socio-demographic profile

3) To determine the response to ART in elderly.

\section{MATERIALS AND METHODS}

This retrospective observational study was conducted in ART plus centre of a tertiary care hospital in north eastern part of India.4085 HIV infected patients have been registered in this centre from 2005 to 2013. A total of 50 patients who are aged over 60 years were registered between may 2005 to December 2013. Records were analyzed on socio-demographical and clinical profile. Baseline CD4 count and one year after treatment, CD4 count was analysed to determine the response to ART. All investigations were done according to NACO Guidelines.The age of 60 years has been accepted as the cut off for old age in most developing countries including India based on socioeconomic situation, age of retirement and life expectancy. ${ }^{(3)}$

Statistitical analysis was done with Ms excel 07 and INSTAT software. $\mathrm{P}$ value $<0.05$ was considered significant.

Inclusion Criteria- Age 60 years or more who are on ART.

Exclusion Criteria-Age less than 60 years

\section{RESULTS AND OBSERVATION}

In the present study, out of 4085 HIV positive registered cases, 50 were elderly.

Graph 1: Prevalence of HIV in Elderly

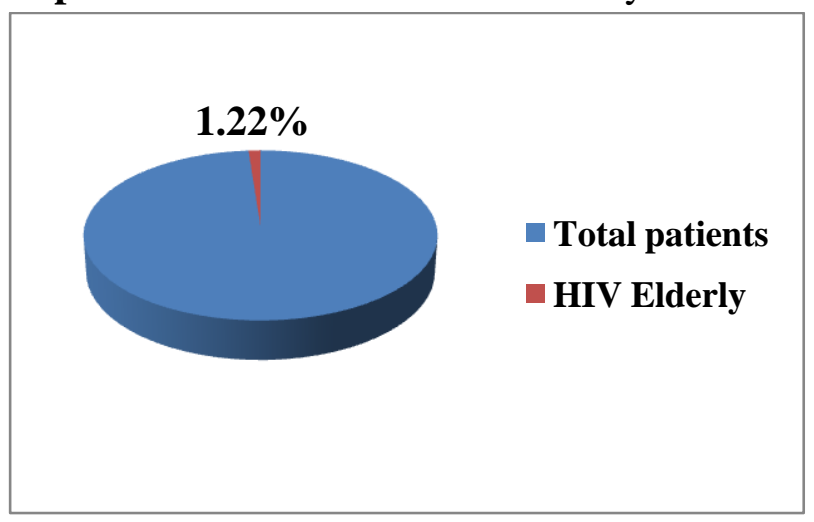

The mean age at presentation was $63.44 \mathrm{yrs}$ with a range from 60-92years. $42(84 \%)$ were males and 8 were females. Male to female ratio was 5.2:1

Table 1: Gender wise distribution

\begin{tabular}{lll}
\hline Gender & Number & Percentage \\
\hline Male & 42 & $84 \%$ \\
Female & 8 & $16 \%$ \\
\hline
\end{tabular}

Table 2: Distribution of patients as per their background

\begin{tabular}{lll}
\hline Background & Number & Percentage \\
\hline Rural & 27 & $54 \%$ \\
Urban & 23 & $46 \%$ \\
\hline
\end{tabular}

Table 3: Distribution of patients as per mode of transmission

\begin{tabular}{lll}
\hline Heterosexual & 34 & $68 \%$ \\
\hline $\begin{array}{l}\text { Injection } \\
\text { user (IDU) }\end{array}$ & drug & $2 \%$ \\
$\begin{array}{l}\text { Blood } \\
\text { transfusion }\end{array}$ & 5 & $10 \%$ \\
Unknown & 10 & $20 \%$ \\
\hline
\end{tabular}


Table 4: Distribution of patients as per their education

\begin{tabular}{lll}
\hline College and above & 15 & $30 \%$ \\
\hline Secondary school & 17 & $34 \%$ \\
Primary school & 12 & $24 \%$ \\
Non literate & 6 & $12 \%$ \\
\hline
\end{tabular}

Table 5: Distribution of patients as per their occupation

\begin{tabular}{lll}
\hline Govt. Employee & 8 & $16 \%$ \\
\hline $\begin{array}{l}\text { Grade IV worker and } \\
\text { labourer }\end{array}$ & 7 & $14 \%$ \\
$\begin{array}{l}\text { Housewife } \\
\text { Private job }\end{array}$ & 7 & $14 \%$ \\
$\begin{array}{l}\text { Bussiness } \\
\text { Retired personals }\end{array}$ & 5 & $10 \%$ \\
$\begin{array}{l}\text { Defense } \\
\text { SSB,Constable) }\end{array}$ & 4 & $10 \%$ \\
Driver & 3 & $8 \%$ \\
Farmer & 3 & $6 \%$ \\
Teacher & 2 & $4 \%$ \\
Lab. Assistance & 2 & $4 \%$ \\
Semi-skilled worker & 2 & $4 \%$ \\
\hline
\end{tabular}

Table 6: Sero-conversion in spouse

\begin{tabular}{ll}
\hline $\begin{array}{l}\text { Total no. of married } \\
\text { pts. }\end{array}$ & Spouse HIV positive \\
\hline $49(98 \%)$ & $18(36 \%)$ \\
\hline
\end{tabular}

Incidence of Opportunistic infection in elderly was $48 \%(24 / 50)$.

Table 7: Distribution of Opportunistic infection in elderl;y

\begin{tabular}{lll}
\hline Extrapulmonary TB & 9 & $37.5 \%$ \\
\hline Pulmonary TB & 7 & $29 \%$ \\
$\begin{array}{l}\text { Oral and oesophageal } \\
\text { candidiasis }\end{array}$ & 6 & $25 \%$ \\
$\begin{array}{l}\text { Others (Genital herpes, } \\
\begin{array}{l}\text { Balanitis, Recurrent } \\
\text { furunculosis) }\end{array}\end{array}$ & $8 \%$ \\
\hline
\end{tabular}

Graph 2: Rise in BMI (Body mass index) after one year of starting ART

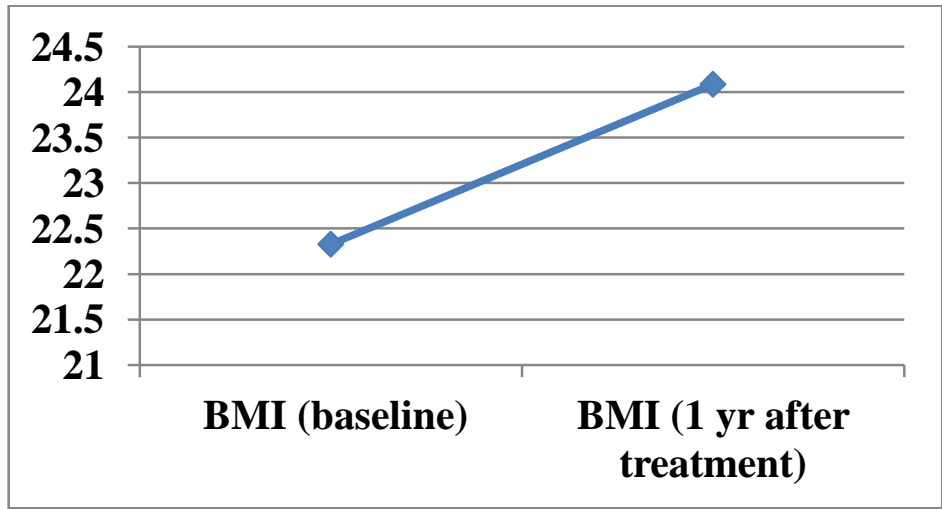

Graph 3: Rise in CD4 cell count after one year of starting ART

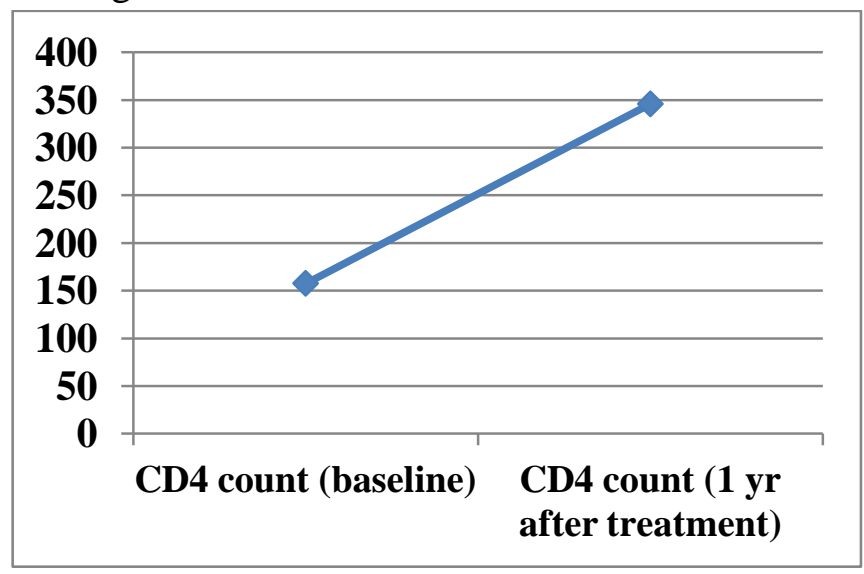

At diagnosis mean BMI was 22.33 and it increased to 24.089 after one year of starting ART. (Graph-1). However the rise in baseline mean BMI and one year after treatment BMI was not significant ( $\mathrm{P}-0.85,95 \% \mathrm{CI}-0.667$ to 1.371 , RR-0.95). Mean CD4 cell count at presentation was 157 cells/dl and after one year of starting ART, mean CD4 cell count raised to 345 cells/dl (Graph-2). The rise in CD4 cell count with treatment was significant. ( $\mathrm{P}-0.0005,95 \% \mathrm{C} \mathrm{I}$ 0.49 to 0.78 , RR-0.6) .Co-morbid conditions are observed in 56\% (28/50). Hypertension followed by diabetes was the commonest co-morbidity observed. Peripheral neuropathy was the most common adverse reaction to ART followed by anaemia, nausea and vomiting. The mean CD4 count at presentation was significantly lower among the patients who died (P -.003, 95\% CI1.2-3.6) compared to those who are alive. Incidence of mortality was also significantly 
higher among elderly patient with co-morbidities. (P value-.0002, 95\% CI-0.1930 to 0.6715).

\section{DISCUSSION}

The adult HIV prevalence in Assam has increased from $0.04 \%$ in 2007 to $0.06 \%$ in 2015 .

928 new HIV cases have been detected in 2015, with an estimated number of 12,090 people living with HIV (PLH) in 2015. Assam is categorised as a low HIV prevalence state with an estimated adult prevalence of 0.06 per cent, lower than national prevalence of 0.26 per cent. However Assam is highly vulnerable for HIV transmission as it is gateway to other north-eastern states and is surrounded by three highly prevalence states of Manipur, Mizoram and Nagaland. The total number of people living with HIV in India was estimated to be 22.9 million in 2009 with adult prevalence of $0.31 \%$. In India as per national AIDS control organization (NACO) HIV/AIDS patients more than 50 years of age constitute the "elderly" HIV-infected populations which accounts for $13.2 \%$ of the total $\mathrm{PLH}^{(4)}$.

In the present study the prevalence of HIV in elderly ( $\geq 60$ years) was found to be $1.22 \%$. (Graph-1). Of new HIV/AIDS cases reported to the Centers for Disease Control and Prevention (CDC) in 2005 , over $15 \%$ were persons 50 years and older while nearly $2 \%$ of new diagnoses were in patients over 65 years of age ${ }^{(5)}$. The low numbers $8 / 50(16 \%)$ of female in this study may not be a true representation of the proportion of females as gender bias, lack of awareness and social stigma and neglect, attached with the disease decrease the number of females attending the HIV clinics. Higher number of male cases may also be explained by the fact that elderly men are more sexually active, practice polygamy , remarry, as compared to elderly women in India.(Table-1) Similar discrepancy in male to female ratio (4:1) was found by Talukdar et al $2014^{(6)}$. Slightly higher number ( 27/50) of elderly patient were reported from rural background as compared to urban (23/50) . (Table-2) This may be due to older persons get settled in their village after retirement and most of the population in this part of country are from rural background. A study from Jaipur, also found majority of patients were from rural area and were referred by treating doctors (97.5\%) (7). Heterosexual 34/50 (68\%) was the most common mode of HIV transmission.(Table-3) Similar findings was reported by Talukdar et al 2014 and Prakash P et al 2005. MSM (Men sex with men) or homosexual contact was not reported in the present study. This may be due to non disclosure associated with various social and religious taboo. On the other hand MSM and Injection drug user make up approximately $50 \%$ of risk factors associated with HIV infection in the older population in US. Among MSM in the US, from 2001 to2004, HIV diagnosis increased in those 45 to 49 years old by $3.1 \%$ and by $6.2 \%$ in persons 50 to 54 years old ${ }^{(8)}$. Nevertheless, heterosexual contact (currently accounting for close to $10 \%$ of HIV infection in older adults) is also on the rise, predominately affecting women and minority groups. In older women, more than $50 \%$ of HIV infections are reported to be due to heterosexual transmission while IDU is much lower (nearly $15 \%)^{(9)}$. An increased number of newly reported infections in the older adult may be due to late HIV testing. The majority of cases are not acute infection, but rather chronic, long standing HIV infection. They should be properly educated regarding safe sex practices and educating them regarding the risk of transmission of HIV is same as for the younger population. Poverty, illiteracy and lack of awareness are playing a major role in the spread of this deadly disease. Most of the patients were employed in some or other way and $17 / 50(34 \%)$ of the patients were educated up to secondary school and 6/50(12\%) were illiterate in this study. (Table-4 \& 5)

Talukdar et al 2014 found illiteracy and unemployment was seen more among elderly women. The higher literacy can be an advantage to educate elderly about nature of HIV and higher rate of employment will make the financial aspect better. Sero-conversion in spouse was reported in 18/50(36\%).(Table-6) In a Tanzanian study conducted among elderly HIV patients, sero- 
positivity was found to be $15 \%$ (18.5\% in men and $9.8 \%$ in women) ${ }^{(10)}$. Incidence of extra pulmonary TB (37.5\%) was slightly higher than pulmonary TB (29\%). (Table-7).This observation is similar to Talukdar et al 2014.

Mean CD4 cell count at the time of diagnosis was 157 cells/dl. The lower mean CD4 count at the time of diagnosis indicates that there is considerable delay in diagnosis among the elderly HIV infected persons. The positive response to ART in elderly can be depicted by significantly increased CD4 cell count and BMI after one year of treatment. (Graph 2\& 3) In one study of 3,015 HIV-infected patients, of whom $13 \%$ were 50 years and older, the mean CD4 cell counts rose significantly within the first six months of ART ; however, mean CD4 cell count increases were significantly higher in younger patients as compared to older patients when stratified by baseline HIV viral load and CD4 cell counts ${ }^{(11)}$. Another study showed that initial CD4 cell count response in older patients was slower during the initial phase of ART, but after 3 years of ART, the CD4 cell counts were not significantly different from that of younger patients ${ }^{(12)}$. In yet other studies by Paredes et al $200{ }^{(13)}$; Grabar et al $2004^{(11)}$; Silverberg et al $2007^{(12)}$ reported that older patients tended to achieve better virologic control compared to younger patients, possibly due to better medication adherence.

Co-morbid conditions were found in 56\% (28/50) of HIV elderly patient. Incidence of mortality was also significantly higher among older HIV patient with co-morbidities. Hypertension followed by diabetes was the commonest co-morbidity observed in this study. Heart disease, diabetes, chronic kidney disease and cancers are among the most prevalent chronic medical conditions affecting older adults and account for some of the leading causes of death. Even among in HIVinfected patients, a higher percentage of older patients have diabetes, chronic respiratory disorders, hypertension, and hyperlipidemia, as well as other cardiac conditions, such as coronary heart disease and heart failure ${ }^{(14,15,16)}$. Peripheral neuropathy was the most common adverse reaction to ART followed by anaemia, nausea and vomiting. Bowman et $\mathrm{al}^{(17)}$ reported that medication side effects in general tend to be higher in older patients, and may be related to age associated declines in hepatic and renal function.

\section{CONCLUSION}

Prevalence of the older people living with HIV in the present study is small, however this is likely to increase in the coming years due to available effective treatment and increase life expectancy .The propensity for under reporting among elderly women is higher and hence deserves special attention. Treatment with ART significantly increases the CD4 cell count. Older people with high risk behaviour and the spouse of the infected person need to be educated for primary and secondary prevention of the disease. Early diagnosis, proper counselling and treatment will not only improve the longevity and quality of life but will also decrease the viral load and transmission of the disease. Co-morbidities should also be addressed properly as it is significantly associated with mortality. Physicians need to be wiser in considering HIV testing among older persons with risk factors and with atypical presentation. Policy makers should also broaden their cohort to include the elderly and bring forth HIV testing and available for elderly individuals.

\section{REFERENCES}

1. National Association of HIV Over Fifty. (2003). Educational Tip Sheet HIV/AIDS and Older Adults. [Online]. http://www.hivoverfifty.org/tip.html

2. Linsk, N. (1994). HIV and the elderly. Families in Society, 75 (6), 362-372.

3. Dey A.B. Butler R, Nyberg J.P. Demography of aging in India, Rosenblatt D.E. and Natrayan V.S. (ed.) Primer on Geriatric care- A clinical approach to older patient. 2002;p1

4. NACO Annual Report 2010-11.

5. CDC] Centers for Disease Control and Prevention. 2006. HIV/AIDS Surveillance Report, 2005 [online]. Accessed June 1, 
2007. URL:http://www.cdc.gov/hiv/topics/surveillance/resources/reports/.

6. Talukdar, A., Parmar, V., Bhattacharya, R., Khanra, D. , Verma, S. , Talukdar, P., Mitra, S. and Roy, K. (2014) HIV Infected Elderly Women: From Rhetoric to Reality-Experience from Eastern India. World Journal of AIDS, 4, 1-7. doi: 10.4236/wja.2014.41001.

7. Prakash, P. and Gupta, P. (2005) HIV at the Doorstep of Geriatrics. Journal of the Indian Academy of Geriatrics, 1, 91-92.

8. Hall HI, Byers RH, Ling Q, et al. 2007. Racial/ethnic and age disparities in HIV prevalence and disease progression among men who have sex with men in the United States. Am J Public Health, 97:1060-6.

9. Espinoza L, Hall HI, Hardnett F, et al. 2007. Characteristics of persons with heterosexually acquired HIV infection, United States 1999-2004. Am J Public Health, 97:144-9.

10. Mtei, L.N. and Pallyango, K.P. (2001) HIV Infection in Elderly Medical Patients. East African Medical Journal, 78, 144-147. http://dx.doi.org/10.4314/eamj.v78i3.9081

11. Grabar S, Kousignian I, Sobel A, et al. 2004. Immunologic and clinical responses to highly active antiretroviral therapy over 50 years of age. Results from the French Hospital Database on HIV. AIDS, 18:2029-38.

12. Silverberg ML, Leyden W, Horberg MA, et al. 2007. Older age and the response to and tolerability of antiretroviral therapy. Arch Intern Med, 167:684-91.

13. Paredes R, Mocroft A, Kirk O, et al. 2000. Predictors of virological success and ensuing failure in HIV-positive patients starting highly active antiretroviral therapy in Europe: results from the EuroSIDA study. Arch Intern Med, 160:1123-32.

14. Skiest DJ, Rubinstien E, Carley N, et al. 1996. The importance of comorbidity in
HIV-infected patients over 55: a retrospective case-control study. Am J Med, 101:605-11.

15. Butt AA, Fultz SL, Kwoh CK, et al. 2004. Risk of diabetes in HIV infected veterans pre- and post-HAART and the role of HCV coinfection.Hepatology, 40:115-9.

16. Palacios R, Santos J, Garcia A, et al. 2006. Impact of highly active antiretroviral therapy on blood pressure in HIV-infected patients. A prospective study in a cohort of naive patients. HIV Med, 7:10-5.

17. Bowman L, Carlstedt BC, Hancock EF, et al. 1996. Adverse drug reaction (ADR) occurrence and evaluation in elderly inpatients. Pharmacoepidemiol Drug Saf, 5:9-18. 